\title{
Evaluation of Antioxidant Properties of Phenolics Extracted from Ananas comosus $\mathrm{L}$.
}

\author{
Adhikarimayum HARIPYAREE, Kshetrimayum GUNESHWOR, Maibam DAMAYANTI
}

Manipur University, Department of Life sciences, Canchipur, Imphal, 795003, India; adbikarimayum_devi@yahoo.in

\begin{abstract}
Phenolics were extracted from the fruit tissues of Ananas comosus L. var. queen, cv. 'Meitei Keehom', a variety of pineapple grown in Manipur, India, after skin peeling, purified and their antioxidant properties were analyzed. The antioxidant properties were assessed based on the ability of fruit phenolics in absolute methanol to scavenge DPPH, superoxide anion radicals and hydroxyl radicals and compared to antioxidant compounds like ascorbic acid and pyragallol. Pineapple fruit phenolics scavenged DPPH, superioxide anion radicals and hydroxyl radicals in a dose dependent way. In DPPH assay, the $\mathrm{IC}_{50}$ values of pineapple phenolics, ascorbic acid and pyragallol were $12.2 \mu \mathrm{g} / \mathrm{ml}, 17.82 \mu \mathrm{g} / \mathrm{ml}$ and $15.92 \mu \mathrm{g} / \mathrm{ml}$ respectively. In superoxide anion and hydroxyl radical scavenging activities, the $\mathrm{IC}_{50}$ values of pineapple phenolics were $11.42 \mu \mathrm{g} / \mathrm{ml}$ and $55.292 \mu \mathrm{g} / \mathrm{ml}$, for ascorbic acid $49.62 \mu \mathrm{g} / \mathrm{ml}, 48.52 \mu \mathrm{g} / \mathrm{ml}$ and that of pyragallol was $15.672 \mu \mathrm{g} /$ $\mathrm{ml}$ and $60.62 \mu \mathrm{g} / \mathrm{ml}$. The $\mathrm{IC}_{50}$ value was lowest in pineapple phenolics than ascorbic acid and pyragallol in DPPH and superoxide anion assays. But it is higher than ascorbic acid and lower than pyragallol in hydroxyl radical assay. The lower the $\mathrm{IC}_{50}$ values, the higher the antioxidant activities. The phenolics extracted from this variety of pineapple exhibit excellent free radical scavenging activity. The result shows that pineapple and its active constituents may be used in further antioxidative therapy.
\end{abstract}

Keywords: Ananas comosus L., antioxidant activity, phenolics, free radicals, ascorbic acid, pyragallol

\section{Introduction}

Ananas comosus L. belongs to Bromeliaceae family is a tropical to subtropical fruit native to Thailand, Phillipines, China, Brazil and India. Ananas comosus L. var. queen cv. 'Meitei Keehom' commonly known as pineapple is a major horticultural indigenous fruit grown in Manipur, India for commercial purposes. The fresh fruits are consumed by the local people and the fruits in the process form are exported. Pineapple contains nutrients which are good for human health. Pineapple fruit contains large amount of phenolics. Although a number of flavonoids and phenolics have been identified in different pineapple cultivars, little information is available about the antioxidant activity of these phenolics. It has been recently shown that phenolics from edible fruits are effective in vitro antioxidants (Gracia-Alonsa et al., 2004; Soong et al., 2004). Plant phenols in red wine exerted cardioprotective effect (Frankel et al., 1995). Polyphenols possess outstanding antioxidant and free radical scavenging properties suggesting a possible protective role in man (Laughton, 1999; Scott et al., 1993). Their antioxidant potential is closely related to the number of hydroxyls, the higher the number, the more potent the chain breaking antioxidant action of the compound (Rafat Hussain et al., 1987). The phenolic content and composition of fruits and vegetables depend on genetic and environmental factor as well as post harvest processing conditions (Robards et al., 1999). Plant phenolics are the largest class of plant secondary metabolites, which serve in plant defense mechanism to counteract reactive oxygen species (ROS) in order to survive and prevent molecular damage. The antioxidant activity of phenolics is related to a number of different mechanisms such as free radical scavenging, hydrogen donation, singlet oxygen quenching, metal ion chelation and acting as a substrate for radical such as superoxide and hydroxide.

The objective of the current study was to evaluate the antioxidant property of phenolics extracted from the fruit tissues of a variety of pineapple by scavenging activity of DPPH (diphenyl-picryl-hydrazyl) and inhibitory effect of superoxide anion radicals and hydroxyl radical scavenging activity.

\section{Materials and methods}

\section{Plant Materials}

Pineapple (Ananas comosus L. var. queen) fruits were collected from local orchard of Manipur, India at commercial mature stage. Mature fruits were collected for successive three years and experiments were carried out.

\section{Extraction and purification of phenolics}

Phenolic compounds were extracted and purified according to Muchuweti et al. (2005). Sample powder (5 g) was extracted two times with ethyl acetate $(15 \mathrm{ml})$ using a magnetic stirrer for $20 \mathrm{~min}$. The fractions were combined and supernatant dried for $30 \mathrm{~min}$ in a dessicator using monohydrate manganese sulphate. The sample was evaporated in a rotary evaporator keeping the bath temperature 
below $35^{\circ} \mathrm{C}$. The sample was dissolved in absolute methanol in $1 \mathrm{mg} / \mathrm{ml}$ and keep at $4^{\circ} \mathrm{C}$ for further experiment.

\section{Antioxidant activity}

The antioxidant capacity of the pineapple fruit phenolic extract was examined by comparing it to the activity of known antioxidants such as ascorbic acid and pyragallol by scavenging of DPPH radical, superoxide anion radicals scavenging activity and hydroxyl radical scavenging activity.

\section{DPPH radical scavenging activity}

Phenolic compounds using DPPH were determined spectrophotometrically, according to the method described by Cuendet et al. (1997). The reaction mixture consisted of $125 \mu \mathrm{M}$ DPPH with $5 \mu \mathrm{g} / \mathrm{ml}, 10 \mu \mathrm{g} / \mathrm{ml}, 15$ $\mu \mathrm{g} / \mathrm{ml}$ and $20 \mu \mathrm{g} / \mathrm{ml}$ of the pineapple phenolics. The stock solutions of $0.1 \mathrm{mM}$ ascorbic acid or $125 \mu \mathrm{g} / \mathrm{ml}$ of pyragallol are used as reference antioxidants. After a $30 \mathrm{~min}$ incubation period in the dark room temperature, the absorbance was read against a blank at $517 \mathrm{~nm}$. Percentage inhibition was determined by comparison with a methanol treated control group. $\times 100$

DPPH decoloration $(\%)=(1-\mathrm{OD}$ sample $/ \mathrm{OD}$ control $)$

The degree of decoloration indicates the free radical scavenging efficiency of the substances.

\section{Inhibition of superoxide radicals}

Superoxide radical generated by hypoxanthine and xanthine oxidase system was determined spectrophotometrically by monitoring the product of NBT (nitroblue tetrazolium). Various concentrations of the extracts were added to the reaction mixture containing $100 \mu \mathrm{l}$ of 25 mM EDTA, ethylene diamine tetra acetic acid ( $\mathrm{pH} 7.4)$, $50 \mu \mathrm{l}$ of $30 \mathrm{mM}$ hypoxanthine in $50 \mathrm{mM} \mathrm{NaOH}, 2 \mathrm{ml}$ of 2 $\mathrm{mM} \mathrm{NBT}$ and the final volume of $3 \mathrm{ml}$ was made up by 50 $\mathrm{mM} \mathrm{PO}_{4}$ buffer ( $\mathrm{pH} 7.4$ ). After adding $100 \mu \mathrm{l}$ of $0.5 \mathrm{U} /$ $\mathrm{ml} \mathrm{Xanthine} \mathrm{Oxidase,} \mathrm{the} \mathrm{reaction} \mathrm{mixture} \mathrm{was} \mathrm{incubated}$ for $30 \mathrm{~min}$ at $25^{\circ} \mathrm{C}$. The absorbance was read at $560 \mathrm{~nm}$ and compared with control sample in which the enzyme, xanthine oxidase was not included.

The percentage inhibition of superoxide radicals was calculated from the optical density of the treated and control sample.

$$
\text { Inhibitory effect }(\%)=\left[\left(\mathrm{A}_{\text {control }}-\mathrm{A}_{\text {sample }}\right) / \mathrm{A}_{\text {control }}\right] \times 100
$$

\section{Hydroxyl Radical (OH) Scavenging activity}

Hydroxyl radical scavenging activity was determined by measuring the competition between deoxyribose and the extracts for hydroxyl radicals generated from the $\mathrm{Fe}^{+3}$ ascorbate/EDTA/ $\mathrm{H}_{2} \mathrm{O}_{2}$ system. The attack of the hydroxyl radical on deoxyribose leads to TBRS formation (Kunchandy and Rao, 1990). Various concentration of the test sample and antioxidant compound were added to the reaction mixture containing $3.0 \mathrm{mM}$ deoxyribose, $0.1 \mathrm{mM}$
$\mathrm{FeCl}_{3,} 0.1 \mathrm{mM}$ EDTA, $0.1 \mathrm{mM}$ ascorbic acid, $1 \mathrm{mM} \mathrm{H}_{2} \mathrm{O}_{2}$ and $20 \mathrm{mM}$ phosphate buffer ( $\mathrm{pH} 7.4)$ and made up to a final volume of $3.0 \mathrm{ml}$. The amount of TBRS formed following $1 \mathrm{~h}$ of incubation at $37^{\circ} \mathrm{C}$ was measured according to the method of Ohkawa et al. (1979). One milliliter of thiobarbituric acid (TBA, 1\%) and $1.0 \mathrm{ml}$ of trichloroacetic acid (TCA, 2.8\%) were mixed with the reaction mixtures in the tubes, and the mixtures were then incubated at $100^{\circ} \mathrm{C}$ for $20 \mathrm{~min}$. After the mixtures were cooled to room temperature, their absorbances at $532 \mathrm{~nm}$ were measured against a blank containing deoxyribose and buffer. Percent inhibition of deoxyribose degradation was calculated with the equation

Inhibitory effect $\%=\left(A_{0}-A_{1}\right) / A_{0} \times 100$

where $A_{0}$ is the absorbance of the control reaction (containing all reagents except the test compound) and $\mathrm{A}_{1}$ is the absorbance of the sample. The absorbances were the means of triplicate measurements. The $\mathrm{IC}_{50}$ (inhibitory concentration) values of all the methods were calculated by using linear regression analysis. All the experiments were repeated thrice.

\section{Statistical analysis}

All analyses were performed in triplicate. The data were expressed as means \pm standard error (SE) in three figures and then analysed by SPSS (version 10.0). One way analysis of variance (ANOVA) and Tukey's multiple comparisons were carried out to test any significant difference between the means. Differences between means at the 5\% level were considered to be significant.

\section{Results and discussion}

\section{DPPH-radical scavenging activity}

The DPPH radical scavenging activity has been used extensively for screening antioxidants from fruit juices or extracts (Sanchez-Moreno, 2002). DPPH can generate stable free radicals in methanolic solution. Free radicals are well known to be able to induce lipid peroxidation. The change in colorization from violet to yellow and subsequent fall in absorbance of the stable free radical was measured. The initial absorbance of the DPPH was 1.21.3. Fig. 1 compares the DPPH radical scavenging activity of pineapple phenolics, ascorbic acid and pyragallol. The pineapple phenolics exhibited a dose dependent DPPH radical scavenging activity. Further more, these pineapple phenolics shows the highest scavenging activity followed by pyragallol and ascorbic acid respectively. At $15 \mu \mathrm{g} / \mathrm{ml}$, the DPPH radical scavenging activities of pineapple phenolics, ascorbic acids and pyragallol were $52.2 \%, 30.7 \%$ and $38.2 \%$ respectively. Many researchers investigated the total antioxidant properties of different fruits and claimed high antioxidant properties of different fruits like apple, red grape, strawberry, pineapple, banana, peach, lemon, orange, pear and grapefruit (Sun et al., 2002). 


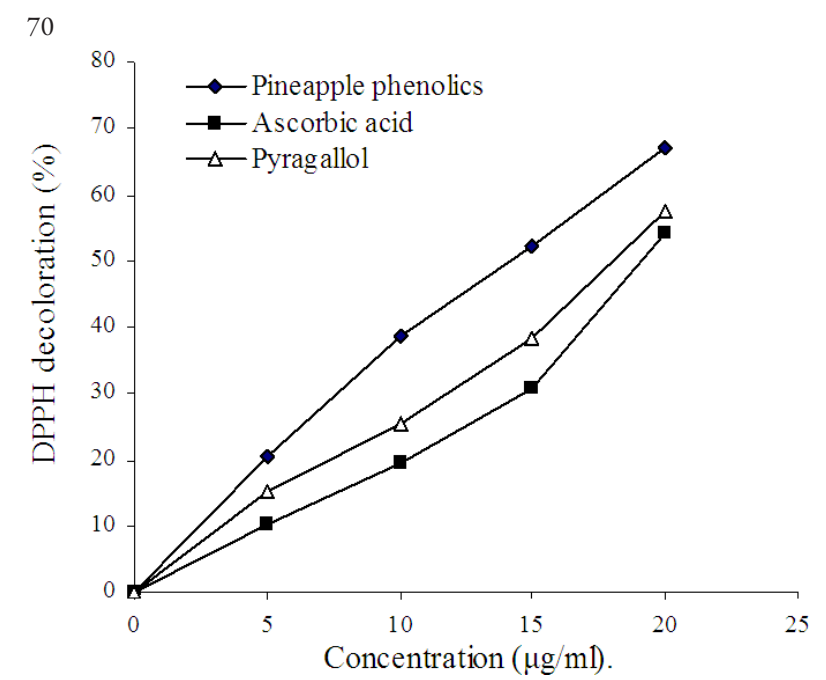

Fig. 1. Scavenging effect of pineapple phenolics on DPPH free radicals

\section{Inbibition of superoxide radicals}

The relative scavenging effects of pineapple phenolics towards superoxide radicals are compared with ascorbic acid and pyragallol in Fig. 2. At $20 \mu \mathrm{g} / \mathrm{ml}$, the superoxide radical scavenging activities of pineapple phenolics, ascorbic acid and pyragallol were $63.43 \%, 20.37 \%$ and $53.32 \%$ respectively.

The hypoxanthine, xanthine oxidase system is frequently used as a generator of superoxide anion radicals. Superoxide anion can damage the biomolecules directly or indirectly by forming reactive hydroxyl radical (Halliwell, 1987). The pineapple phenolics were found to scavenge the superoxide radicals in a dose dependent response. Superoxide radicals are produced by a number of cellular reactions, including various enzyme systems like peroxidase, lipoxygenase and xanthine oxidase. Superoxide radical plays an important role in plant tissues and is involved in the formation of other cell damaging free radicals (Bloknina et al., 2003).

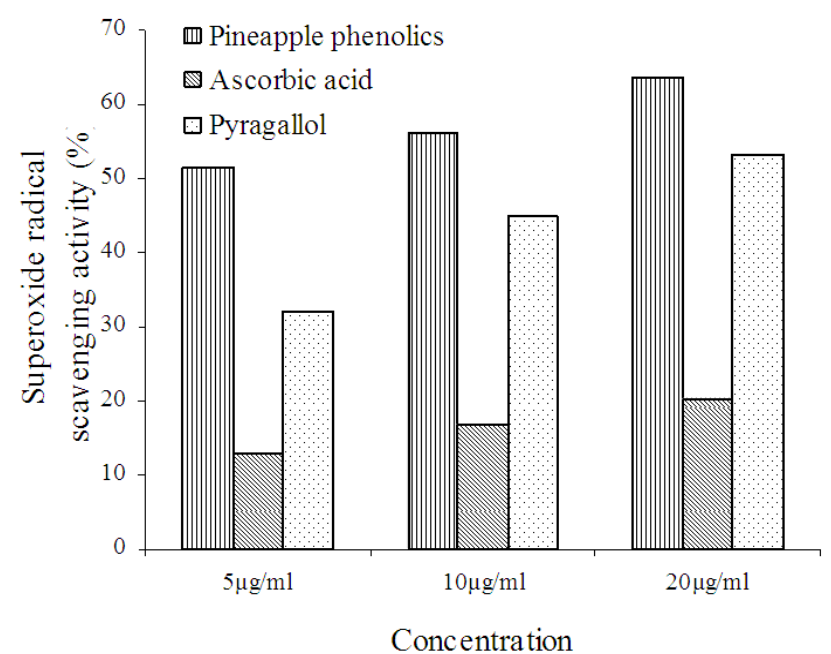

Fig. 2. Superoxide radical scavenging activity of pineapple phenolics

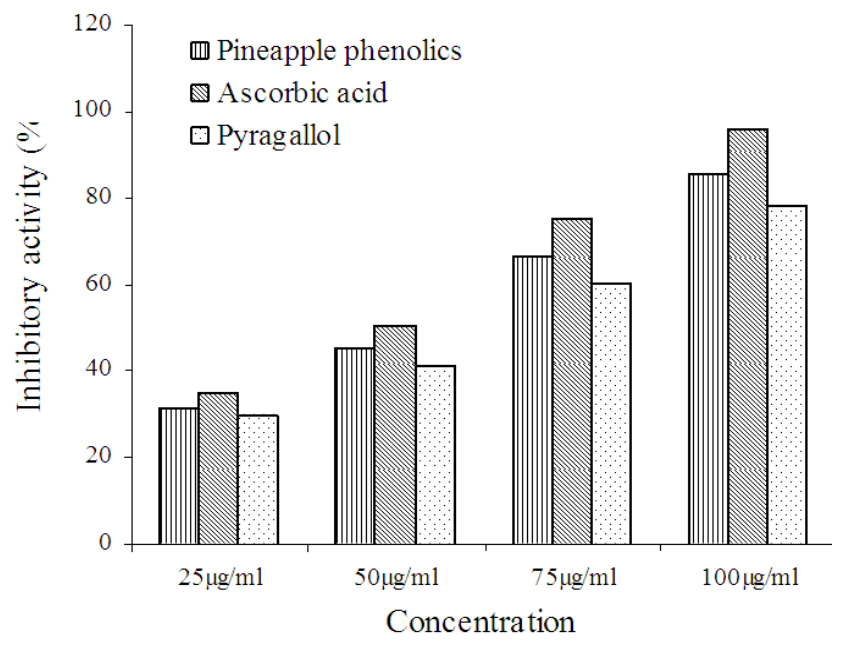

Fig. 3. Hydroxyl radical scavenging activity of pineapple phenolics

\section{Hydroxyl radical $(\mathrm{OH})$ radical scavenging activity}

The hydroxyl radical scavenging activity of pineapple phenolics was determined according to deoxyribose degradation in Fenton type reaction system. Fig. 3 shows the concentration dependent inhibition of hydroxyl radicals by pineapple phenolics, ascorbic acid and pyragallol. At $100 \mu \mathrm{g} / \mathrm{ml}$, the hydroxyl radical scavenging activity of pineapple phenolics, ascorbic acid and pyragallol are $85.4 \%$, $96.6 \%$ and $78.5 \%$ respectively. Hydroxyl radical can be formed by the Fenton reaction in the presence of reduced transition metals such as $\mathrm{Fe}^{2+}$ and $\mathrm{H}_{2} \mathrm{O}_{2}$ which is known to be the most reactive of all the reduced forms of di-oxygen, capable of damaging almost every molecules found in living cells (Rollete-Labelle et al., 1998). Deoxyribose was oxidized when exposed to hydroxyl radicals generated by Fenton reagent and the oxidation degradation can be detected by heating the products with TBA and measuring the absorbance at $532 \mathrm{~nm}$ (Cheng et al., 2003). The hydroxyl radical scavenging activity of pineapple phenolics was found to be lowered than those of ascorbic acid and a little higher than pyragallol. Similar results of dose dependent inhibition were reported for litchi phenolics (Duan et al., 2007).

Tab. 1. shows the $\mathrm{IC}_{50}$ values of the methanolic extracts of pineapple phenolics and two standard compound ascorbic acid and pyragallol. The DPPH, superoxide and hydroxyl radical scavenging activities of pineapple phenolics compares well with that of the same dose of ascorbic

Tab. 1. $\mathrm{IC}_{50}$ values of methanolic extracts of pineapple phenolics and two standard compounds on DPPH, superoxide and hydroxyl free radical inhibition

\begin{tabular}{cccc}
\hline \multirow{2}{*}{ Sample } & \multicolumn{3}{c}{$\mathrm{IC}_{50}$ values $(\mu \mathrm{g} / \mathrm{ml})$} \\
\cline { 2 - 4 } & DPPH & Superoxide & Hydroxyl \\
\hline Pineapple phenolics & 12.25 & 11.42 & 55.29 \\
Ascorbic acid & 17.84 & 49.61 & 48.45 \\
Pyragallol & 15.90 & 15.67 & 60.63 \\
\hline
\end{tabular}


acid and pyragallol. Pineapple phenolic exhibited higher $\mathrm{DPPH}$ and superoxide scavenging activity compared to ascorbic acid and pyragallol. But in hydroxyl radical scavenging activity, it exhibit higher activity than pyragallol, a lower activity than ascorbic acid. $\mathrm{IC}_{50}$ value is defined as the concentration of the sample extracts causing 50 percent inhibition of absorbance; a lower $\mathrm{IC}_{50}$ value would reflect greater antioxidant activity of the sample.

Various research data about the antioxidant capacity of fruits and vegetables in the literature clearly show that the methods in many stages of research from sample preparation to antioxidant activity measurement vary highly and it is almost impossible to compare the results of one investigation with another (Kolayli et al., 2003).On the other hand, when the experiments were carried out, no significant variation was recorded in the scavenging activity of the mature fruits of this pineapple variety in successive years.

\section{Conclusions}

The phenolics extracted from this variety of pineapple exhibited excellent antioxidant activity. The results of all the assays are in agreement that methanol extracts of pine apple phenolics displayed high antioxidant activity. They act as hydrogen donating agent in the DPPH assay, were effective in scavenging superoxide anion produced by hypoxanthine-xanthine oxidase and hydroxyl radicals generated from Fenton reaction. These effects may be correlated with its phenolic structure, which can react with a free radical to form the phenoxyl radicals. These results show that pineapple and its active constituents may be used in future antioxidative therapy and provides a valuable source of nutraceutical supplements.

\section{Acknowledgements}

One of the author (AH) is grateful to the DST, New Delhi for financial assistance provided as Women Scientist (WOS-A) fellowship (vide grant no. SR/WOS-A/LS58/2008).

\section{References}

Bloknina, O., E. Virolianen and K.V. Fagerstedt (2003). Antioxidant oxidative damage and oxygen deprivation stress. A Review. Ann. Bot. 91:179-194.

Cheng, Z., L. Yuanzong and W. Chang (2003). Kinetic deoxyribose degradation assay and its application in assessing the antioxidant activities of phenolic compounds in Fentontype reaction system. Anal. Chim. Acta. 478:129-137.

Cuendet, M. K., K. Hostettmann and O. Potterat (1997). Iridoid glucosides with free radical scavenging properties from Fragarea blumei. Helvetica Chimica. Acta. 80:11441152.
Duan, X., W. Genfu and J. Yueming (2007). Evaluation of antioxidant properties of Litchi fruit phenolics in relation to pericarp browing prevention. Molecules 12:759-771.

Frankel, E. N., A. L. Waterhouse, P. L. Teissedre (1995). Principal phenolic phytochemicals in selected California wines and between organisms. J. Agric. Food chem. 43:890-894.

Gracia-Alonsa, M., S. De Pascual-Teresa, C. Santos-Buelga and J. C. Rivas-Gonzalo (2004). Evaluation of antioxidant activity and phenolic content of selected fruit seeds. Food chem. 84:13-18.

Halliwell, B. (1987). Oxidants and human disease: some new concepts. FASEB J. 1:358-364.

Kolayli, S., M. Kucuk, C. Duran, F. Candan and B. Dincer (2003). Chemical and antioxidant properties of Laucerasus officinalis Roem. (Cherry Laurel) fruit grown in Black sea region. J. Agric. Food Chem. 51(25):7489-7494.

Kunchandy, E. and M. N. A. Rao (1990). Oxygen radical scavenging activity of curcumin. Int. J. Pharm. 58:237-240.

Laughton, M. J., P. J. Evans, M. A. Moroney, J. R. S. Howlt and B. Halliwell (1991). Inhibition of Mammalian 5 lipoxygenase and cyclo-oxygenase by flavonoids and phenolic dietary additives: relationships to antioxidant activity and to iron reducing ability, Biochem. Pharmacol. 42:1673-1681.

Ohkawa, H., N. Ohishi and K. Yagi (1979). Assay for lipid peroxidase in animal tissues by thiobarbituric acid reaction. Anal. Biochem. 95:351-358.

Rafat Hussain, S., J. Cillard and P. Cillard (1989). Hydroxyl radical scavenging activity of flavonoids. Phytochemistry 26(9):2489-2491.

Robards, K., P. D. Prenjlere, G. Tucker, P. Swatsitang and W. Glover (1999). Phenolic compounds and their role in oxidative processes in fruits. Food Chem. 66:401-436.

Sanchez-Moreno, C. (2002). Methods used to evaluate the free radical scavenging activity in foods and biological systems. Food Sci. Technol. Int. 8:21-137.

Scott, B. C., J. Butter, B. Halliwell and O. Aruoma (1993). Evaluation of the antioxidant actions of ferulic acid and catechins. Free Rad. Res. Commun. 19(4):241-253.

Soong, Y. Y. and P. J. Barlow (2004). Antioxidant activity and phenolic content of selected fruit seeds. Food chem. 88:411417.

Sun, J., Y. F. Chu, X. Wu and R. H. Liu (2002). Antioxidant and antiproliferative activities of common fruits. J. Agr. Food Chem. 50:7449-7454. 